\title{
A Study on the Characteristics of Patients Who do not Recover in the Long-term Treatment of First Episode Schizophrenia
}

\author{
Amresh Shrivastava', Sagar Karia ${ }^{2}$, Nilesh Shah ${ }^{2}$, Avinash De Sousa ${ }^{2}$
}

\section{Amresh Shrivastava ${ }^{1}$, Sagar Karia”, Nilesh Shah², Avinash De Sousa ${ }^{2}$}

\author{
'Parkwood Institute of Mental Health \\ Care and Associate Scientist, Lawson \\ Health Research Institute, London, \\ CANADA. \\ ${ }^{2}$ Department of Psychiatry, Lokmanya \\ Tilak Municipal Medical College, \\ Mumbai, Maharashtra, INDIA.
}

\section{Correspondence \\ Dr. Avinash De Sousa, \\ Research Associate, Department of Psy- chiatry, Lokmanya Tilak Municipal Medical College, Carmel, Francis Road, Santacruz West, Mumbai, Maharashtra, INDIA. \\ Mobile no: +9122 26460002 \\ Email: avinashdes888@gmail.com \\ History \\ - Submission Date: 22-01-2019 \\ - Revised Date: 19-05-2019 \\ - Accepted Date: 31-10-2019}

DOI : 10.5530/ijmedph.2019.3.20

Article Available online

http://www.ijmedph.org/v9/i3

\section{Copyright}

(C) 2019 Phcog.Net. This is an openaccess article distributed under the terms of the Creative Commons Attribution 4.0 International license.

\begin{abstract}
Background: Despite revolutionary advances in treatment of Schizophrenia, about $30-40 \%$ patient do not achieve a state of recovery. This limited outcome interferes achieving a positive outcome and wellness. Long term outcome in schizophrenia has been poorly studied. There is a dearth of longitudinal studies that determine factors affecting outcome in patients with first episode of schizophrenia. While short term studies have yielded some findings, long term studies in this domain are rare. The present study looks at the characteristics and factors that affect non recovery in patients with first episode schizophrenia over a ten year duration. Methodology: 101 patients attending a non government private psychiatric hospital were followed up over a 10 year period and assessed for recovery and outcome parameters using the Clinical Global Impression Scale (CGIS $\leq$ 2), the Positive and Negative Symptoms Scale for Schizophrenia (PANSS) based on RSWG criteria, Hamilton Depression Rating Scale (HDRS), Quality of Life Scale (QOLS), Global Assessment of Functioning (GAF) and the Abnormal Involuntary Movement Scale (AIMS) for extrapyramidal symptoms. Independent living and family burden were studied on a 1 to 5 point likert scale with 1 being worst and 5 being good. Non recovery was defined as Good outcome was defined as a score of 2 or less on CGIS. The results were analyzed statistically and presented. Results: When non recovered subjects were assessed on various parameters, significant reductions in total PANSS scores, positive and negative symptom scores, depression scores on the HDRS ( $p<0.0001$ in all cases). The non recovered group had significantly greater number of hospitalizations $(p<0.0001)$, more disorganized behavior $(p<0.0002)$, greater interpersonal issues ( $p=0.0013$ ) and poor outcome on independent living ( $p<0.0001)$. Assessment of the baseline characteristics of both groups revealed that age at the time of entry into the study was lower in the non-recovery group ( $p<0.0001)$ while greater negative symptom scores $(p<0.0001)$, greater depression scores $(p<0.0001)$ and greater aggression was present. Conclusion: The present study shows that early age of onset of psychosis and presence of severe negative symptoms are significantly related to future non-response in long term outcome of first episode schizophrenia. It is also important mentioning that symptom reduction alone is insufficient when looked as an outcome measure in schizophrenia.
\end{abstract}

Key words: Outcome, Schizophrenia, Recovery, Non-recovery, Positive symptoms, Negative symptoms, HDRS, PANSS, CGI-S, Hospitalizations.

\section{INTRODUCTION}

Schizophrenia is a complex and debilitating brain disorder that typically emerges in late adolescence and early adulthood. ${ }^{1}$ Schizophrenia afflicts approximately $1 \%$ of the population worldwide incurringsubstantial individual, family and societal burden ${ }^{2}$ along with shortened life span. ${ }^{3}$ There is a dearth of studies that have measured outcome in schizophrenia. ${ }^{4} \mathrm{~A}$ review that looked at outcomes in schizophrenia over the past century observed that the outcome in terms of complete recovery and resolution of symptoms has never been more than $25-40 \% .^{5}$ It has been argued by many researchers that outcome of schizophrenia needs to be measured on clinical and psychosocial parameters. ${ }^{6}$ Lack of uniformity and clarity in measuring outcome has been the main cause for confusion in understanding outcome in schizophrenia. ${ }^{7}$ However even when social and clinical outcomes are

considered, it does not show an encouraging trend ${ }^{8}$ and some authors have even posited questions as to whether patients that suffer from schizophrenia ever recover. ${ }^{9}$

An analysis of outcome literature reveals that better outcomes have been reported from Asian and other developing countries. ${ }^{10}$ In the International Pilot Study on Schizophrenia, Indian researchers have reported a good outcome for schizophrenia with the trend being favorable as in $>60 \%$ recover over a 15 year period. ${ }^{11}$ The Madras longitudinal study has also shown good outcome in range of $65-75 \%$ for schizophrenia in India. ${ }^{12}$ Short term outcomes particularly in first episode psychosis has been encouraging as seen in studies. ${ }^{13}$ The response rate measured shows $<30 \%$ relapses in first episode psychosis and good response in about $82 \%$ cases in short term as-

Cite this article : Shrivastava A, Karia S, Shah N, Sousa AD. A Study on the Characteristics of Patients Who do not Recover in the Long-term Treatment of First Episode Schizophrenia. Int J Med Public Health. 2019;9(3):81-6. 
sessments. ${ }^{14,15}$ The main challenge in treatment has been to sustain the outcome for longer periods in these patients. There is evidence that good outcome sustains up to 2 years but it may decline in the long term management of schizophrenia. ${ }^{16}$ Despite revolutionary treatment advances in schizophrenia a number of patients still fail to show a complete recovery from the disorder. ${ }^{17}$

Antipsychotic drugs form the mainstream of treatment in schizophrenia. It is not clearly known what role antipsychotics may play in the treatment and maintenance of treatment or remission in schizophrenia in the long term course ${ }^{18}$ Identification of the subjects, who are not likely to respond, is important not only from a clinical perspective but also from an economic and public health point of view. ${ }^{19}$ Significant work has been done regarding the determinants of course and outcome in schizophrenia but early identification of non-responders would be important to assist and plan the comprehensive management of the patient. The present research examines factors for non-response in first episode schizophrenia patients who has been treated for a period of ten years.

Despite revolutionary advances in treatment of schizophrenia, about 30$40 \%$ patient do not achieve a state of recovery. This limited outcome interferes achieving a positive outcome and wellness. Wellness as outcome criteria for schizophrenia is currently under extensive investigation. Studies suggest that a true outcome in schizophrenia is recovery with includes personal and positive state of health which is return to a state of wellness. It is recognised that there are number of barriers to achieve the state of wellness which are personal, social, environmental, illness, treatment related and other factors. In this paper we try to examine the long term outcome of first episode schizophrenia. We believe that these factors may be responsible for the limited and poor state of outcome in some cases.

\section{MATERIALS AND METHODS}

This study was carried out in a non-governmental psychiatric hospital certified as a psychiatric facility by the State Government as per the Indian Mental Health Act 1983 in Mumbai; India. The study period spanned from January 1992 to January 2005. An Independent Ethics Commission approved the study. Patients who were available at the end of ten years from a cohort of first episode schizophrenia (patients experiencing their first episode of psychotic symptoms and seeking treatment) were assessed for clinical recovery. The scales used in the assessment were the Clinical Global Impression Scale (CGI-S), ${ }^{20}$ the Positive and Negative Symptoms Scale for Schizophrenia (PANSS), ${ }^{21}$ Hamilton Depression Rating Scale (HDRS), ${ }^{22}$ Quality of Life Scale (QOLS), ${ }^{23}$ Global Assessment of Functioning (GAF), ${ }^{24}$ Abnormal Involuntary Movement Scale (AIMS) for extrapyramidal symptoms. ${ }^{25}$ Independent living and family burden were studied on a 1 to 5 point liker scale with 1 being worst and 5 being good. Good outcome was defined as a score of 2 or less on CGIS. On using the PANSS, the RSWG criteria ${ }^{26}$ based on ratings at 8 focal symptoms in positive, negative and general psychopathology subscales of PANSS (P1, P2, P3, N1, N4, N6, G5, G9) were applied for clinical remission; patients were judged to be in clinical remission according to a severity criterion (scores obtained at each of these items had to be $\leq 3$ points, indicating mild severity of symptoms).

Descriptive statistics for demographic characteristics and patient scores at baseline and after ten years of follow-up were calculated. To test the degree of change between baseline and final follow-up assessments, paired $t$-tests were used for continuous variables and McNamara's chisquare tests were used for dichotomous variables. Logistic regression was used to evaluate invariable associations between baseline characteristics and recovery as defined by the CGI-S. Lack of fit was evaluated using the Hosmer-Lemeshow goodness of fit statistic. The seven clinical parameters included negative symptoms, positive symptoms, disorganization, hospitalization in the past two years, suicidality, extra pyramidal function and aggression at the ten year follow-up.

\section{RESULTS}

There are two main findings in this study that were evaluated first were the clinical features of patients who did not show improvement at the end of ten years, despite consistent treatment and clinical features at the very beginning which tended to indicate candidates vulnerable for nonresponse.

A total of 101 subjects made up the study population and this further divided into recovered $(n=61)$ and non recovered subjects $(n=40)$. When non recovered subjects were assessed on various parameters (Table 1), significant reductions in total PANSS scores, positive and negative symptom scores, depression scores on the HDRS and improvement on GAF were noted ( $p<0.0001$ in all cases). Larger number of patients had shown aggressive and violent behavior and disorganized behavior at the baseline. Medications had no effect on recovery of the subjects except Aripiprazole which was used by larger number of patients in the non recovered group ( $p=0.0203$ ) (Table 2 ).

When recovered and non recovered subjects were compared after a 10 year period, the subjects with non recover had significantly greater scores on the PANSS $(p<0.002)$, greater positive symptom scores $(p=0.0241)$, greater negative symptom scores $(p=0.0003)$ and lower quality of life scores $(p<0.0001)$. Both groups did not differ on GAF scores (Table 3 ). The non recovered group had significantly greater number of hospitalizations $(p<0.0001)$, more disorganized behavior $(p<0.0002)$, greater interpersonal issues $(p=0.0013)$ and poor outcome on independent living $(p<0.0001)$ (Table 3$)$.

When the baseline characteristics of both groups were compared at the start of the study, age was lower in the non recovery group $(p<0.0001)$ while greater negative symptom scores $(p<0.0001)$, greater depression scores $(p<0.0001)$ and greater aggression was present (Table 4$)$. It is worthwhile noting that positive symptom scores, duration of illness at the start of the study, total PANSS scores, CGI scores and gender played no role in recovery (Table 4 ).

\section{DISCUSSION}

As pointed out by some researchers, the issue of what the actual rates and correlates of recovery are is an empirical question. ${ }^{27}$ Researchers have recently examined five elements of recovery for 130 participants from the United States with co-occurring substance abuse and schizophrenia spectrum disorders. Over a 10 -year period they reported that $63 \%$ had achieved symptom remission as defined as having mean BPRS scale scores of " 3 " or less, $62 \%$ were in a later phase of substance abuse treatment and at the time abstinent from substances and 57\% were living independently. Beyond that, $41.4 \%$ of participants had worked in a competitive job in the past year, $49 \%$ had regular healthy social contacts and $58 \%$ reported acceptable satisfaction with their overall circumstances. Importantly, the attainment of one element of recovery was often not linked to the attainment of others. ${ }^{28}$

Indian studies have linked duration of untreated psychosis as a factor in the long term outcome of schizophrenia. ${ }^{29}$ Long term outcome is directly related negatively to delays in seeking treatment. A longitudinal 10 year study in first episode schizophrenia patients demonstrated that treatments received, social support, compliance and delay in treatment all affect outcome in schizophrenia. ${ }^{30} \mathrm{~A}$ review on Indian research in schizophrenia has also emphasized that elucidating factors affecting recovery and non recovery in schizophrenia shall help in the primary prevention of the problem itself. ${ }^{31}$ Women in India has been shown to often have 


\begin{tabular}{|c|c|c|c|c|c|}
\hline \multicolumn{6}{|c|}{ Mean (SD) } \\
\hline Positive Symptoms & $26.4(4.2)$ & $9.8(3.8)$ & $16.5(5.8)$ & $14.7-18.4$ & $\mathrm{t}=24.99, p<0.0001^{\star a}$ \\
\hline Negative Symptoms & $27.5(5.7)$ & $15.4(6.0)$ & $12.1(9.1)$ & $9.1-15.0$ & $\mathrm{t}=19.639, p<0.0001^{\star a}$ \\
\hline HDRS & $20.6(5.6)$ & $14.1(4.9)$ & $6.5(7.8)$ & $4.0-9.0$ & $\mathrm{t}=7.3410, p<0.0001^{\star a}$ \\
\hline GAF & $48.7(11.3)$ & $79.9(10.7)$ & $-31.2(12.2)$ & $-35.3--27.1$ & $\mathrm{t}=18.223, p<0.0001^{\star a}$ \\
\hline \multirow{2}{*}{\multicolumn{2}{|c|}{ Outcome Parameter }} & Baseline & \multicolumn{2}{|r|}{ At 10 years } & Statistical analysis \\
\hline & & $\mathrm{N}(\%)$ & & & \\
\hline \multicolumn{2}{|c|}{$\mathrm{EPS} \leq 2$} & $38(95.0 \%)$ & \multicolumn{2}{|r|}{$25(62.5 \%)$} & $p=0.0007^{\star b}$ \\
\hline \multicolumn{2}{|c|}{ Disturbed Independent Living } & $40(100.0 \%)$ & \multicolumn{2}{|r|}{$35(87.5 \%)$} & $p=0.0547 \mathrm{NS}^{\mathrm{b}}$ \\
\hline \multicolumn{2}{|c|}{ Aggression } & $33(82.5 \%)$ & \multicolumn{2}{|r|}{$17(42.5 \%)$} & $\mathrm{X}^{2}=12, p=0.0005^{\star c}$ \\
\hline \multicolumn{2}{|c|}{ Family Burden } & $2(5.6 \%)$ & \multicolumn{2}{|r|}{$22(61.1 \%)$} & $p<0.0001^{* b}$ \\
\hline \multicolumn{2}{|c|}{ Suicidality - Occasional or Occasional with plan } & $27(75.0 \%)$ & \multicolumn{2}{|r|}{$20(55.6 \%)$} & $\mathrm{X}^{2}=1.857, p=0.173 \mathrm{NS}$ \\
\hline \multicolumn{2}{|c|}{$\mathrm{GAF} \leq 80$} & $36(90 \%)$ & \multicolumn{2}{|r|}{$20(55.6 \%)$} & $p=0.0002^{* \mathrm{~b}}$ \\
\hline
\end{tabular}

${ }^{*}$ significant $(p<0.05)$, NS-not significant, a Paired t test used in the calculation, ${ }^{b}$ Fisher's test used in the calculation due to small cell sizes, ${ }^{\mathrm{c}} \mathrm{Chi}$ square test used in the analysis.

\begin{tabular}{|c|c|c|c|}
\hline \multirow[t]{2}{*}{ Medication } & \multicolumn{2}{|c|}{ Recovered } & \multirow[t]{2}{*}{ Statistical Analysis } \\
\hline & No $(n=40)$ & $\begin{array}{c}\text { Yes } \\
(n=61)\end{array}$ & \\
\hline Clozapine & $6(15.0 \%)$ & $4(6.6 \%)$ & $p=0.1882^{\star a}$ \\
\hline Risperidone & $10(25.0 \%)$ & $17(27.9 \%)$ & $\mathrm{X}^{2}=0.008, p=0.9293 \mathrm{NS}^{\mathrm{b}}$ \\
\hline Olanzapine & $8(20.0 \%)$ & $12(19.7 \%)$ & $\mathrm{X}^{2}=0.002, p=0.9677 \mathrm{NS}^{\mathrm{b}}$ \\
\hline Quetiapine & $9(22.5 \%)$ & $12(19.7 \%)$ & $\mathrm{X}^{2}=0.008, p=0.9293 \mathrm{NS}^{\mathrm{b}}$ \\
\hline Aripiprazole & $11(27.5 \%)$ & $5(8.2 \%)$ & $\mathrm{X}^{2}=5.382, p=0.0203^{* \mathrm{~b}}$ \\
\hline Ziprasidone & $3(7.5 \%)$ & $3(4.9 \%)$ & $p=0.6788 \mathrm{NS}^{\mathrm{a}}$ \\
\hline
\end{tabular}

*significant $(p<0.05)$, NS-not significant

Comparisons made using Chi-square test except for Clozapine and Ziprasidone for which Fisher's Exact two-tailed test was used due to small expected cell sizes.

better outcomes in schizophrenia than men while delay in seeking treatment is often longer in the case of women. ${ }^{32}$

Several authors have suggested that the earliest phases of recovery may involve seeing oneself as a person whose story is worthy of being told, whereas the later stages of recovery involve achieving mastery in the process of constructing and negotiating meaning around the course of the events of one's life. ${ }^{33}$

Most clinicians measure outcome in schizophrenia depending upon their own judgment. In this sample of 101 patients 40 patients did not show clinical response at the end of ten years treatment. The patients who did not respond also showed significant reduction in psychopathology (PANSS total, positive and negative symptom and HDRS scores) and increase in functioning though the level of recovery was short of qualifying as improved on CGIS. More than $60 \%$ subjects who did not respond were free from active positive negative and affective symptoms. This suggests that a decrease in symptoms or absence of symptoms alone is not good enough improvement in majority of the patients. Improved outcome perhaps is much more than mere reduction in psychopathology. ${ }^{34}$ These patients also show presence of more negative symptoms and more re-hospitalization. Baseline characteristics of subjects who did not respond was typically early age of onset, severe psychopathology and significant burden on the families.It has been consistently reported since the historical times that early onset schizophrenia has poor prognosis. ${ }^{35}$ Biological advancements in schizophrenia clearly show that the illness starts much earlier and pathogenesis of the disorder may be rooted in early development. ${ }^{36}$ Contrarily increased duration of untreated psychosis leads to more pronounced neurobiological changes ${ }^{37}$ and it is therefore clear that younger age of onset of symptoms is an indicator of poorer response.

Our main finding, the presence of severe negative symptoms seen amongst non-responders in the early stage is consistent with reported literature..$^{38}$ Negative symptoms have been long recognized as a symptom domain of schizophrenia and it has been consistently reported that negative symptoms are more resistant to treatment and account for most part of dysfunction caused in schizophrenia possibly due to its close association with cognitive dysfunction. ${ }^{39}$ Negative symptoms represent a subgroup of schizophrenia which is shown to have specific neurobiological cognitive, imaging and neurophysiological changes.In this background our findings are consistent with reported literature that presence of negative symptoms indicates non-response. 


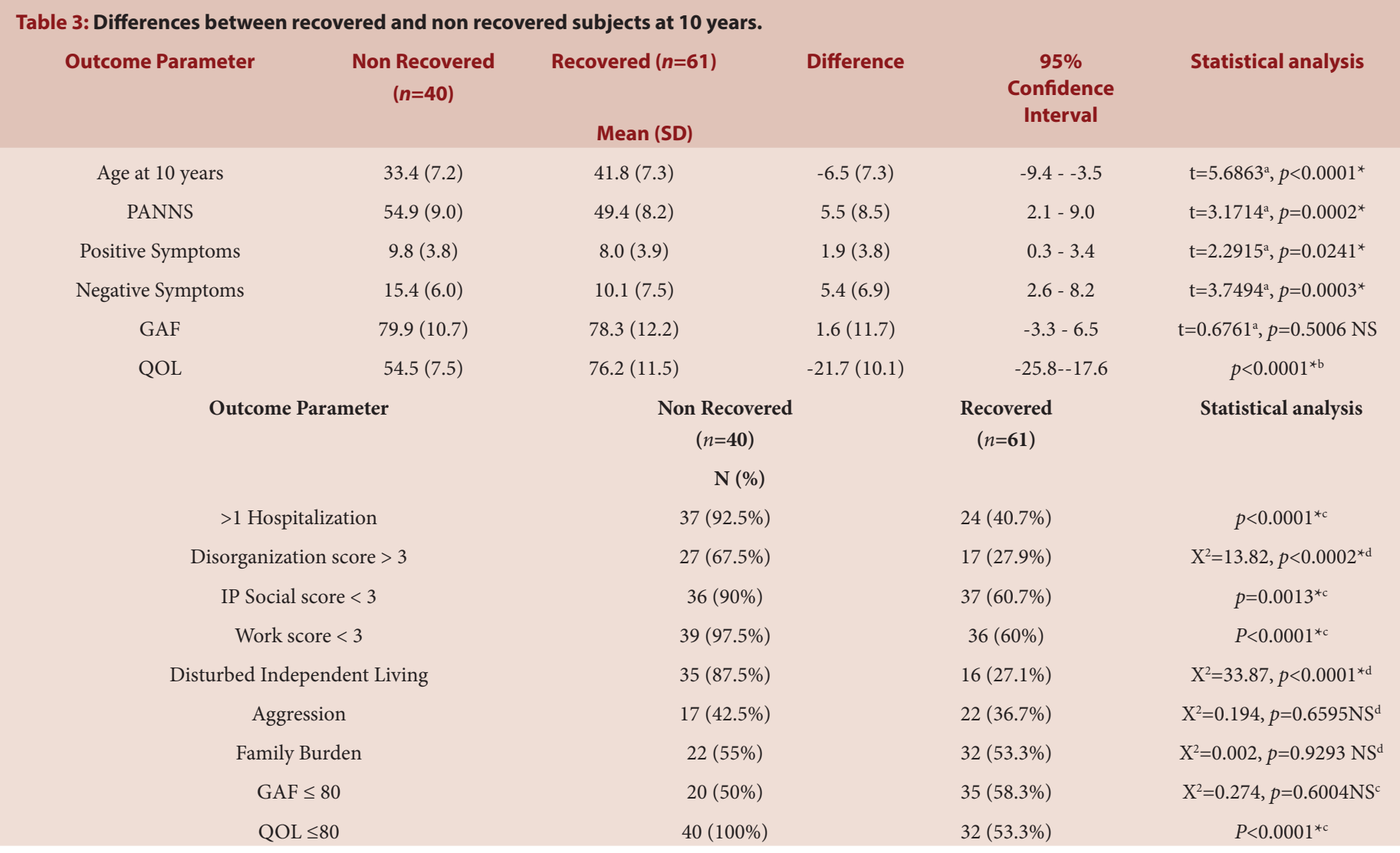

${ }^{*}$ significant $(p<0.05)$, NS-not significant, ${ }^{a}$ Unpaired t test used in the calculation, ${ }^{b}$ Wilcoxon sum of the ranks used as data was not normal in distribution. ${ }^{c}$ Fisher exact test used in the calculation due to small cell sizes, ${ }^{\mathrm{d}} \mathrm{Chi}$ square test used in the analysis.

\begin{tabular}{|c|c|c|c|}
\hline Outcome Parameter & $\begin{array}{l}\text { Non Recovered } \\
\qquad(n=40)\end{array}$ & Recovered $(n=61)$ & Statistical analysis \\
\hline \multicolumn{4}{|c|}{ Mean (SD) } \\
\hline Durn. of symptoms & $10.8(5.7)$ & $14.0(8.0)$ & $\mathrm{t}=2.1898^{\mathrm{a}}, p<0.0309^{*}$ \\
\hline Age at baseline & $24.4(7.1)$ & $31.8(7.6)$ & $\mathrm{t}=4.9104^{\mathrm{a}}, p<0.0001^{*}$ \\
\hline Negative Symptoms & $27.5(5.7)$ & $20.9(6.4)$ & $\mathrm{t}=5.2887^{\mathrm{a}}, p<0.0001^{*}$ \\
\hline Global Psychopath. & $49.6(15.6)$ & $57.4(17.0)$ & $\mathrm{t}=2.3288^{\mathrm{a}}, p=0.0219^{*}$ \\
\hline HDRS & $20.6(5.6)$ & $15.4(5.6)$ & $\mathrm{t}=4.5640^{\mathrm{a}}, p<0.0001^{*}$ \\
\hline GAF & $48.7(11.3)$ & $48.0(10.9)$ & $\mathrm{t}=0.3111^{\mathrm{a}}, p=0.7564 \mathrm{NS}$ \\
\hline Disorganization $>3$ & $36(90)$ & $52(86.7)$ & $p=0.5574 \mathrm{NS}^{c}$ \\
\hline $\mathrm{EPS} \leq 2$ & $38(95)$ & $57(95)$ & $p=0.9899 \mathrm{NS}^{c}$ \\
\hline Aggression > 2 & $33(82.5)$ & $31(51.7)$ & $\mathrm{X}^{2}=9.125, p=0.0025^{\star \mathrm{b}}$ \\
\hline Family Burden $>3$ & $2(5.6)$ & $2(3.3)$ & $p=0.6474 \mathrm{NS}^{\mathrm{c}}$ \\
\hline
\end{tabular}

${ }^{*}$ significant $(p<0.05)$, NS-not significant.

${ }^{\mathrm{a}}$ Unpaired $\mathrm{t}$ test used in the assessment, ${ }^{\mathrm{b}} \mathrm{Chi}$ square test used in the assessment, ${ }^{\mathrm{C}}$ Fisher's exact test used in the assessment due to small cell sizes. 
Another finding in this study is presence of severe psychopathology for non responsive patients as indicated by presence of positive, negative and affective symptoms as features of non response. This is in line of reported data in literature. ${ }^{40}$ Severe illness is also related to more social dysfunction and cognitive dysfunction. Besides, severity of illness leads to frequent and increased duration of hospitalization, longerneuroleptic exposure, greater isolation from one's community and family. ${ }^{41}$ There appears to be a direct link between severe psychopathology at the onset and poorer outcome in long run. ${ }^{42}$

Non recovered patients had significantly more severe depressive symptoms at the baseline. Most of the studies report that affective symptoms are common across the course of schizophrenia, more common in acute episode and in general show better response to treatment. ${ }^{43}$ In the present study however sever depressive symptoms are seen at baseline among non-responders, which shows significant decrease at the ten years, suggesting response to treatment. At the beginning severe depressive symptoms are seen existing together with negative symptoms. Research data indicates a significant overlap in genetic susceptibility categories of psychotic disorders and affective disorders. ${ }^{44}$ Depressive symptoms in schizophrenia may arise as primary or secondary to negative symptoms. ${ }^{45}$ Severe depression at the beginning is possibly reflective of depression secondary to negative symptoms and primary depressive symptoms might have responded well. Thus if severe depression is present in acute phase along with severe negative symptoms, then it may be predictive of treatment non response. ${ }^{46}$ Our findings are consistent with research available.

Though with poor reliability, the study also shows that type of antipsychotic drug is not related with treatment response or non response in long term. Antipsychotic drugs have limited role in determining outcome of schizophrenia per se. ${ }^{47}$ While good response to antipsychotic in early phase and first episode in short term is well established, its response in chronic schizophrenia is limited ${ }^{48}$ and in this study all patients were on atypical antipsychotics. Since a number of the patients were on two or three antipsychotic, this finding cannot be interpreted with certainty. Over all the subjects who did not recover were more severely ill causing significant impact on their families in early stages of the illness though they do show reduction in symptoms over 10 years duration? The present study shows that early age of onset of psychosis and presence of severe negative symptoms are significantly related to future non-response in long term outcome of first episode schizophrenia. Further prospective longitudinal studies in larger populations are needed to establish firmly the findings obtained from this study. It is clear from our study that despite early intervention, adequate social and pharmacological treatment with good compliance, outcome is limited all three, social, clinical as well as functional dimension. This poses few challenges for the treatment. Would there be further deterioration in the patient and how do we go about achieving wellness.

Studies also suggest that neuroplasticity and neuronal regeneration is an important feature in recovering phase of treatment. The patient may need a new care plan at this state of evaluation and strategies of treatment can be modified which may include early identification of treatment resistance, early identification of modifiable factors in the illness, re-evaluation the 'person' who has schizophrenia, patient-centric rehabilitation programs, specific psychosocial interventions, smoking cessation treatments in schizophrenia, management of physical disorder and side effects of medication, re-assessment of pharmacotherapy, improvement in social milieu, lifestyle treatment - diet, weight management, exercise, yoga, cognitive behavior therapies and focus on spirituality.

\section{CONCLUSION}

There is a need to enhance hope with better care and further research in schizophrenia. ${ }^{49,50}$ It is important that these be incorporated in the long term.

\section{CONFLICT OF INTEREST}

The authors declare that there are no conflicts of interest.

\section{REFERENCES}

1. Gutiérrez-Maldonado J, Caqueo-Urízar A, Kavanagh DJ. Burden of care and general health in families of patients with schizophrenia. Soc Psych Psychiatr Epidemiol. 2005;40(11):899-904.

2. Awad AG, Voruganti LN. The burden of schizophrenia on caregivers. Pharmacoeconomics. 2008;26(2):149-62.

3. Mangalore R, Knapp MJ. Cost of schizophrenia in England. Ment Health Policy Econ. 2007:10(1):23-41.

4. Hegarty JD, Baldessarini RJ, Tohen M, Waternaux C, Oepen G. One hundred years of schizophrenia: A meta-analysis of the outcome literature. Am J Psychiatry. 1994;151(10):1409-16.

5. Albert N, Bertelsen M, Thorup A, Petersen L, Jeppesen P, Quack LP, et al. Predictors of recovery from psychosis Analyses of clinical and social factors associated with recovery among patients with first-episode psychosis after 5 years. Schizophr Res. 2011;125(2-3):257-66.

6. Harrow M, Grossman LS, Jobe TH, Herbener ES. Do patients with schizophrenia ever show periods of recovery?. A 15-year multi-follow-up study Schizophr Bull. 2005;31(3):723-34

7. Green MF, Kern RS, Heaton RK. Longitudinal studies of cognition and functional outcome in schizophrenia: Implications for MATRICS. Schizophr Res. 2004;72(1):41-51.

8. Breier A, Schreiber JL, Dyer J, Pickar D. National Institute of Mental Health longitudinal study of chronic schizophrenia: Prognosis and predictors of outcome. Arch Gen Psychiatry. 1991;48(3):239-46.

9. Brekke J, Kay DD, Lee KS, Green MF. Biosocial pathways to functional outcome in schizophrenia. Schizophr Res. 2005;80(2):213-25.

10. Hopper K, Wanderling J. Revisiting the developed versus developing country distinction in course and outcome in schizophrenia: Results from ISoS, the WHO collaborative followup project. Schizophr Bull. 2000;26(4):835-46.

11. Dube KC, Kumar N, Dube S. Long term course and outcome of the Agra cases in the International Pilot Study of Schizophrenia Acta Psychiatr Scand. $1984 ; 70(2): 170-9$.

12. Thara R. 25 years of schizophrenia: The Madras longitudinal study. Indian J Psychiatry. 2012;54(2):134-7.

13. Perkins DO, Gu H, Boteva K, Lieberman JA. Relationship between duration of untreated psychosis and outcome in first-episode schizophrenia: A critical review and meta-analysis. Am J Psychiatry. 2005;162(10):1785-804.

14. Marshall M, Lewis S, Lockwood A, Drake R, Jones P, Croudace T. Association between duration of untreated psychosis and outcome in cohorts of first-episode patients: A systematic review. Arch Gen Psychiatry. 2005;62(9):975-83.

15. Petersen L, Nordentoft M, Jeppesen P, ØHLENSCHLAEGER J, Thorup A, Christensen $\mathrm{T} \varnothing$, et al. Improving 1-year outcome in first-episode psychosis. $\mathrm{Br} \mathrm{JP}$ Sychiatry. 2005;187(48):s98-103.

16. Cullberg J, Levander S, Holmqvist R, Mattsson M, Wieselgren IM. One-yea outcome in first episode psychosis patients in the Swedish Parachute project. Acta Psychiatr Scand. 2002;106(4):276-85.

17. Robinson DG, Woerner MG, McMeniman M, Mendelowitz A, Bilder RM. Symptomatic and functional recovery from a first episode of schizophrenia or schizoaffective disorder. Am J Psychiatry. 2004;161(3):473-9.

18. Lieberman JA, Stroup TS, McEvoy JP, Swartz MS, Rosenheck RA, Perkins DO, et al. Effectiveness of antipsychotic drugs in patients with chronic schizophrenia. New Eng J Med. 2005;353(12):1209-23.

19. Novick D, Haro JM, Suarez D, Vieta E, Naber D. Recovery in the outpatient setting: 36-month results from the Schizophrenia Outpatients Health Outcomes (SOHO) study. Schizophr Res. 2009;108(1):223-30.

20. Guy W. Clinical global impression scale. The ECDEU Assessment Manual for Psychopharmacology-Revised Volume DHEW Publ No ADM. 1976;76(338):2182.

21. Leucht S, Kane JM, Kissling W, Hamann J, Etschel E, Engel RR. What does the PANSS mean?. Schizophr Res. 2005;79(2):231-8

22. Hamilton M. A rating scale for depression. J Neurol Neurosurg Psychiatry 1960;23(1):56-62.

23. Heinrichs DW, HanlonTE, CarpenterWT. The Quality of Life Scale: An instrument for rating the schizophrenic deficit syndrome. Schizophr Bull. 1984;10(3):388-98. 
24. Jones SH, Thornicroft G, Coffey M, Dunn G. A brief mental health outcome scale-reliability and validity of the Global Assessment of Functioning (GAF). Br J Psychiatry. 1995;166(5):654-9.

25. Guy W. Abnormal involuntary movement scale (AIMS). ECDEU assessment manual for psychopharmacology. Rockville, MD: US Dept. of Health, Education and Welfare. 1976;338:534-7.

26. Andreasen NC, JrCarpenter WT, Kane JM, Lasser RA, Marder SR, Weinberger DR. Remission in schizophrenia: Proposed criteria and rationale for consensus. Am J Psychiatry. 2005;162(3):441-9.

27. Silverstein SM, Bellack AS. A scientific agenda for the concept of recovery as it applies to schizophrenia. Clin Psychol Rev. 2008;28(7):1108-24.

28. Drake RE, McHugo GJ, Xie H, Fox M, Packard J, Helmstetter B. Ten-year recovery outcomes for clients with co-occurring schizophrenia and substance use disorders. Schizophr Bull. 2006;32(3):464-73.

29. Shrivastava A, Shah N, Johnston M, Stitt L, Thakkar M, Chinasamy G. Effect of duration of untreated psychosis on long term outcome in people hospitalized with first episode psychosis. Indian J Psychiatry. 2010;52(2):164-7.

30. Shrivastava A, Shah N, Johnston M, Stitt L, Thakkar M. Prediction of long term outcome in first episode schizophrenia: A 10 year follow up study. Indian J Psychiatry. 2010;52(4):320-6.

31. Kulhara P, Shah R, Aarya KR. An overview of Indian research in schizophrenia. Indian J Psychiatry. 2010;52(7):159-72.

32. Thara R, Kamath S. Women and schizophrenia. Indian J Psychiatry. 2015;57(Suppl 2):S246-51.

33. Roe $\mathrm{D}$, Mashiach-Eizenberg $\mathrm{M}$, Lysaker $\mathrm{PH}$. The relation between objective and subjective domains of recovery among persons with schizophrenia-related disorders. Schizophr Res. 2011;131(1):133-8.

34. Häfner H, DerHeiden AW, Behrens S, GattazWF, Hambrecht M, Löffler W, et al. Causes and consequences of the gender difference in age at onset of schizophrenia. Schizophr Bull. 1998;24(1):99-113.

35. Verdoux H, Geddes JR, Takei N, Lawrie SM, Bovet P, Eagles JM, et al. Obstetric complications and age at onset in schizophrenia: An international collaborative meta-analysis of individual patient data. Am J Psychiatry. 1997;154(9):1220-7.

36. Vourdas A, Pipe R, Corrigall R, Frangou S. Increased developmental deviance and premorbid dysfunction in early onset schizophrenia. Schizophr Res. 2003;62(1):13-22.
37. Drake RJ, Haley CJ, Akhtar S, Lewis SW. Causes and consequences of duration of untreated psychosis in schizophrenia. Br J of Psychiatry. 2000;177(6):511-5.

38. Andreasen NC, Flaum M, Swayze VW, Tyrrell G, Arndt S. Positive and negative symptoms in schizophrenia: A critical reappraisal. Arch Gen Psychiatry 1990;47(7):615-21.

39. Blanchard JJ, Cohen AS. The structure of negative symptoms within schizophrenia: Implications for assessment. Schizophr Bull. 2006;32(2):238-45.

40. Bartels SJ, Drake RE. Depressive symptoms in schizophrenia: Comprehensive differential diagnosis. Compr Psychiatry. 1988;29(5):467-83.

41. Lewandowski KE, Barrantes-Vidal N, Nelson-Gray RO, Clancy C, Kepley HO, Kwapil TR. Anxiety and depression symptoms in psychometrically identified schizotypy. Schizophr Res. 2006;83(2):225-35.

42. Sax KW, Strakowski SM, Keck PE, Upadhyaya VH, West SA, et al. Relationships among negative, positive and depressive symptoms in schizophrenia and psychotic depression. Br J Psychiatry. 1996;168(1):68-71.

43. Buchanan RW. Persistent negative symptoms in schizophrenia: An overview. Schizophr Bull. 2007;33(4):1013-22.

44. Lichtenstein P, Yip BH, Björk C, Pawitan Y, Cannon TD, Sullivan PF, et al. Common genetic determinants of schizophrenia and bipolar disorder in Swedish families: A population-based study. Lancet. 2009;373(9659):234-9.

45. Singh SP, Singh V, Kar N, Chan K. Efficacy of antidepressants in treating the negative symptoms of chronic schizophrenia: Meta-analysis. Br J Psychiatry. 2010;197(3):174-9.

46. Collins AA, Remington G, Coulter K, Birkett K. Depression in schizophrenia: A comparison of three measures. Schizophr Res. 1996;20(1):205-9.

47. Geddes J, Freemantle N, Harrison P, Bebbington P. Atypical antipsychotics in the treatment of schizophrenia: Systematic overview and meta-regression analysis. BMJ. 2000;321(7273):1371-6

48. Leucht S, Corves C, Arbter D, Engel RR, Li C, Davis JM. Second-generation versus first-generation antipsychotic drugs for schizophrenia: A meta-analysis. Lancet. 2009;373(9657):31-41.

49. Thara R. Schizophrenia-enhancing hope with better care and research. Ind J Med Res. 2014;140(4):469-71.

50. Patel V, Cohen A, Thara R, Gureje O. Is the outcome of schizophrenia better in developing countries. Rev Bras Psiquiatr. 2006;28(2):149-52.

Cite this article : Shrivastava A, Karia S, Shah N, Sousa AD. A Study on the Characteristics of Patients Who do not Recover in the Long-term Treatment of First Episode Schizophrenia. Int J Med Public Health. 2019;9(3):81-6. 